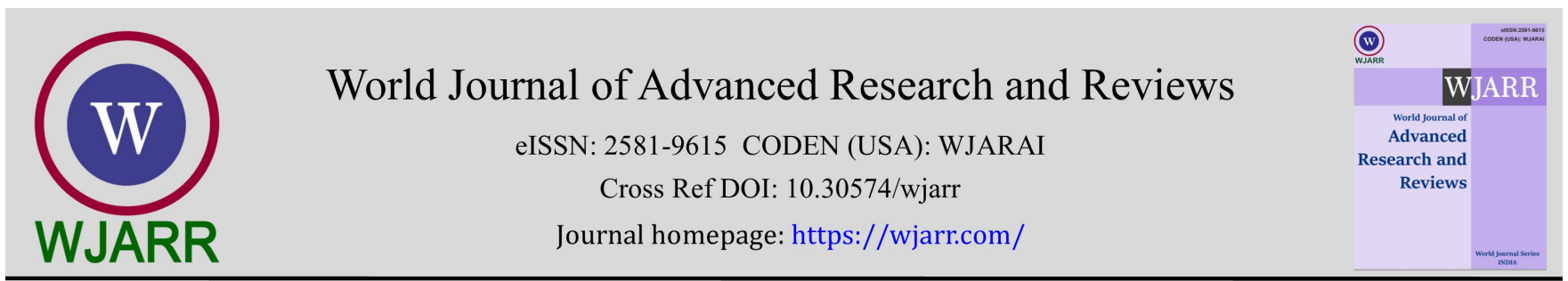

(RESEARCH ARTiClE)

\title{
Contemplation and interaction? An intervention in public schools to motivate the concern in hygiene and transmission of diseases
}

\author{
Barbara Fialho Carvalho Sampaio 1, 2*, Jaqueline Polizeli Rodrigues 1, Luciana Regina Meireles 1,2, Yugo \\ Gushiken ${ }^{1}$, Gabriela Marques ${ }^{1}$ and Heitor Franco de Andrade Jr ${ }^{1,2}$ \\ ${ }^{1}$ Institute of Tropical Medicine of São Paulo - University of São Paulo - IMT-USP. \\ ${ }^{2}$ School of Medicine - University of São Paulo - FMUSP.
}

World Journal of Advanced Research and Reviews, 2022, 13(02), 108-115

Publication history: Received on 28 December 2021; revised on 05 February 2022; accepted on 07 February 2022

Article DOI: https://doi.org/10.30574/wjarr.2022.13.2.0114

\begin{abstract}
Non family health education is controversial by the different family models and is done in a contemplative way, which generates small fixation of concepts or behavioral changes and the child may have flawed personal sanitary concepts. As the school offers only a contemplative view, individual interactive experiences could pinpoint and emphasize these concepts. With this, the Institute of Tropical Medicine of the University of São Paulo and the Faculty of Medicine of the University of São Paulo, with the support of the Pro-Rectory of Extension and Culture of University of São Paulo, we constructed an interactive exhibition for students of public schools of the fundamental cycle, addressing the essential concepts of disease transmission and prevention. An initial contemplative view was offered during the waiting queue, then each individual performs experiments of interpersonal contact, transmission by fomites, variation of agents, and "contamination" is demonstrated by fluorescent lighting. The interaction was presented in 5 public schools, with intense collaboration of the students and teachers, with 1300 students participating in all experiments with more than $70 \%$ participation. Events of this type, which raise awareness about hygiene and the transmission and prevention of communicable diseases can be done interactively among students, allowing greater fixation and greater acceptance. The exposition is interactive with active participation of students in essays and revelation of landmark events, such as demonstrating interpersonal contamination at various levels of personal relationship.
\end{abstract}

Keywords: Health hygiene; Prevention, school; Scientific exposition; Interaction

\section{Introduction}

The construction of hygiene concepts and the prevention of interpersonal transmission of diseases was a maternal attribution before the involvement of women in the partial provision of the family income. This childhood training in hygiene was transmitted by the mother at home, with simple but effective concepts in early childhood, in a female role that is now partially abandoned. The prevention of diseases through the use of vaccines, the improvement of sanitary conditions, the urbanization of most of the population and the early involvement of women in the labor market, led to a lower occurrence of infectious diseases. This dismantled the father-provider-mother-caregiver family model, with less time of contact between the child and the parents and the partial transfer of responsibility for establishing hygiene concepts, passed to the day care center and/or school.

The National Curriculum Parameters constitute the official curriculum plan for Brazilian elementary education, which in its context of traditional disciplines and transversal themes does not prioritize hygiene concepts, leaving the mother/family or preschool responsible for hygiene concepts. Teachers do not have this objective in their goals and

\footnotetext{
${ }^{*}$ Corresponding author: Barbara Fialho Carvalho Sampaio

Institute of Tropical Medicine of São Paulo - University of São Paulo - IMT-USP.

Copyright (C) 2022 Author(s) retain the copyright of this article. This article is published under the terms of the Creative Commons Attribution Liscense 4.0.
} 
even when this occurs there is no systematic approach to their training, especially in pedagogues or science/biology teachers, as there seems to be a prejudgment that communicable diseases are relatively controlled or they have means of prevention, as is the case with influenza vaccination, but no interest in the ways in which it is transmitted, only poorly presented commercial interests, for example, the use of commercial products for the prevention of transmission, as a shield were created without the need for hygiene.

The school curriculum is not a motivator for the establishment of essential concepts for the citizen, and alternatives should be tried in students, where interpersonal interaction is at the same time minimal, due to the reduction of people per family and the intense activity of electronic media, which transfer to passive visualization of interpersonal experiences; or maximally, by the need for more intimate contacts for their social approval, like small adults suddenly involved in sensual activities due to environmental pressure [1].

According to the Director-General of Health of Portugal [2], it is in childhood and adolescence that healthy lifestyles are acquired and consolidated, whose maintenance throughout life will allow gains in health and a more rational use of health services in the country. Future. On the other hand, the reluctance of young people to seek clarification, information or help from health services or health professionals is known. In view of this finding, the school can play a fundamental role in the acquisition of healthy lifestyles and in the prevention of harmful behaviors, by investing in health promotion among children and young people. For health authorities, the strategy to save the unwise use of health services in the future.

The Ottawa Charter [3] defines the concept of health promotion as: “...the process aimed at enabling individuals to exercise greater control over their health and over the factors that may affect it by reducing the factors that may affect it. Result in risk and favoring those who are protected and healthy... health develops and is generated within the framework of daily life: in work and recreation education centers. Health is the result of the care that each individual gives to himself and to others, of the ability to make decisions, to control his own life and to guarantee that the society in which he lives offers all its members the possibility of enjoying a good state of health" [3].

Health education is assumed, as well as the form of excellence to obtain gains in individual health and, consequently, in the community, in the medium and long term [4].

Most health and risk behavior problems are associated with the environment and lifestyles and can be prevented or significantly reduced through effective School Health Programs. Studies evaluating the cost and effectiveness of preventive interventions with schoolchildren have shown that $€ 1$ spent on health promotion today represents a gain of $€ 14$ on health services tomorrow (National School Health Plan) [5].

Scientific dissemination is important for the democratization of society, making it freer, responsible and more scientifically cultured, reducing the existing imbalance between the cultural and the intellectual. In the 1980s, relevant activities with the purpose of public dissemination of science appeared in Brazil and in other countries, which are science centers and contemporary science museums, increasing the level of knowledge of the citizen, through science and technological exhibitions [6].

Interactive exhibitions are important in the process of social inclusion, because they favor conditions to expand scientific knowledge focused on health and disease prevention.

The objective of the interactive exhibition is to spread the prevention of diseases, through the experience and interaction with everyday situations, stimulating the formation of health knowledge.

Curiosity and observation of reality through interactive and playful experimentation is important to facilitate reflection with the care needed to have a healthier life.

The action of the exhibition is effective when the public is school, since the students are induced to change the experiments, and after this interaction they are able to evidence and correlate the experiences with the prevention of diseases worked on.

The school constitutes a valuable environment for the development of educational actions in the health area. In addition, the school environment can dynamically involve the participation and interest of students, teachers and staff, reinforcing the ability to transform acquired knowledge into changes in habits. 
"Contagion" is demonstrated by fluorescence, revealed by specific lighting. The contemplation of the didactic content is done with videos, leaflets and other interactive materials. The construction of these materials always involved the exhibitor, so that both the video and the experience had the same conductors. After that, there was a complete cycle of 20 minutes, with 6 activity stations and at the exit there was a demonstration of possible contamination, discussion and solution of doubts. The first and second stations showed direct transmission by droplets, with color detection by ninhydrin, and indirect, through objects with fluorescent ink detectable by ultraviolet light. The third and fourth season showed virus recombination, by means of building blocks inserted into pig and chicken models (simulating Influenza virus recombination). And in the last stations, students participated in a controlled party with fluorescent props, gloves for personal protection, music and lighting for 5 minutes. Students had the option of using the glove or not. Those who didn't use it had their hands painted with fluorescent paint and were able to see later by ultraviolet light. The entire process was monitored by undergraduate and graduate students, who were also the actors in the explanatory videos.

Health education is extremely important when it is desired to change attitudes towards diseases, so we have to prioritize the promotion of health education. Educating in health is to understand the problems that affect a certain community and became the population aware of these problems to look for solutions. In this way, education must be based on dialogue, on the exchange of experiences and there must be a link between scientific knowledge and popular knowledge [7].

Tropical Diseases have a constant occurrence above $5 \%$ of hospitalizations in our country despite efforts to eradicate them. Tourism has promoted greater mobility of people, generating an exposure of vulnerable people to these diseases and their reintroduction in unaffected areas. The IMTSP has maintained intense research activity on these diseases, especially in their diagnosis and prevention, with extension activities aimed at raising awareness of communities at risk or vulnerable groups. In view of this, we built an Itinerant Exhibition, based on ways of preventing respiratory transmission diseases, such as influenza, mumps, rubella and measles, and sexually transmitted diseases, such as Syphilis, Herpes, Aids and HPV, in addition to toxoplasmosis, aimed at high school students of elementary education in Public Schools in the State of São Paulo.

Thus, within this scope of neglect of hygiene teaching, we suggest the use of an interactive exhibition with simple experiences to motivate the fixation of hygiene concepts within dynamic ways more suitable for the new populations of young people.

\section{Material and methods}

\subsection{Selection of schools and number of students}

The São Paulo Center-West Education Board has 75 schools, working in three cycles, Elementary School I, Elementary School II and High School. 36 schools are Elementary School I, 37 Elementary School II and 37 schools are High School. Some have more than one cycle.

Of these 37 schools for Elementary Education II, the Central-West Teaching Directorate selected 5 schools randomly, for the execution of the interactive exhibition to promote teaching in collective health.

The intervention was carried out in groups of 10 to 15 students at same time per environment, from the 7 th to 8 th grade of Elementary School II. This research constituted an experimental study, which was developed in two moments: 1st elaboration and construction of the exhibition and 2 nd intervention and interaction with students in the exhibition.

\subsection{Physical construction of the exhibition, expenditure items and staff}

For the educational action, several integrated actions were developed, basically consisting of activities divided into 03 environments with 06 stations. Environment 01 addressed the transmission of respiratory diseases, by droplets (station 01 ) and by fomites (station 02). Environment 02 addressed the recombination of swine flu and avian influenza viruses (station 03) with an explanation of the activity in station 04. Environment 03 addressed the transmission and prevention of sexually transmitted diseases (STDs) with 2 support stations, the 05 (dressing room) and station 06 (interaction with the activity).

The selection of the 03 environments was carried out by tents with a roof, low cost and easy to transport. We also built boxes with materials for each environment, which transformed the exhibition into 03 tents measuring $1.30 \mathrm{x} \emptyset 0.40 \mathrm{~m}$ and 06 boxes measuring $0.60 \times 0.5 \times 0.4 \mathrm{~m}$. Each room also had a collapsible table, provided by the site or transported by us. An electrical wiring was prepared in an isolated area with a single input and output for the various electrical 
equipment used in the exhibition. Thus, we built a spatial exhibition that could be set up in the schoolyard, in a covered or uncovered area.

The tent areas were separated by printed fabrics containing information about the local interactive activity and the main concepts of disease transmission. The printed fabrics are easy to transport and assemble and allow you to define which side will be visible to spectators in the queue.

In order to isolate the exhibition environment, we opted for plastic chains and pedestals, which allowed the internal view and increased the students' interest in the activities in the queue for the route of the 06 stations.

For the reception and waiting lines, we placed two totems with televisions that continuously played explanatory films about the exhibition, built by the student monitors themselves, which made possible an interaction between the waiting line and the monitoring of the exhibition, which generated an increase in the credibility of the exposure.

When leaving the exhibition area, information leaflets on all the diseases covered were distributed, prepared by the team from the Protozoology Laboratory of the Instituto de Medicina Tropical de São Paulo. The pamphlets and videos were used as educational materials for the proposed actions, providing them as a vehicle for simplified instruction within the reach of participating students, their families and other school members (principals, vice-principals, coordinators, teachers and others). Employees). The content was briefly addressed, with didactic and enlightening illustrations, whose objective was that the communication reached all those involved, articulated to the notion of the value and importance of the themes.

\subsection{Description of activities - Queue}

The approach to didactic content started in the waiting line, with videos, leaflets and totems in which there were explanations about contagion, symptoms and prevention of all the diseases covered in the exhibition. After waiting, there was a complete cycle of 20 minutes, where students entered after interacting in the queue with information about the topics that would be worked on in the activities.

\subsection{Transmission of Respiratory Diseases: Splashes and Fomites}

This activity was carried out in environment 01 and stations 01 (sprays) and 02 (fomites) and showed the students the direct transmission by sprinklers, with color detection by ninhydrin, and indirect, through objects with fluorescent ink detectable by ultraviolet light. In the first experiment, transmission by droplets, the students placed their heads in the opening of a plastic box with white paper at the bottom. The students spoke a tongue twister that was written on the bottom of the box, which caused droplets of saliva to splash onto the white paper. After spraying nihydrin, the places that acquired a lilac, purplish tone were the regions contaminated with saliva. In saliva we find several proteins, such as enzymes used in digestion and these proteins have free amines that react with ninhydrin and give rise to a purple compound. This reaction is also used in fingerprint identification. After carrying out the activity, the monitor questioned the students about the transmission of diseases, and basic questions about hygiene. In the second experiment, transmission by fomites, the students observed several objects, apparently clean, on a table. After the concepts and information provided by the monitor, about what a fomite is and its importance for the transmission of diseases, a UV light was placed on the objects and the students could observe that all were marked with a fluorescence, showing that even without able to see, the objects can be contaminated and be vehicles of disease transmission. After the experience, the monitor talked with the students about personal hygiene, about the importance of washing hands and about the transmission of respiratory diseases and those caused by other microorganisms.

\subsection{Swine flu and avian influenza virus recombination}

This activity was carried out in environment 02 and stations 03 (virus gene recombination activity) and 04 (explanation of the activity) and showed the students the basic principle of how a virus recombines to form a new virus. With lego pieces, the monitor created an example of what a virus would look like and asks the students to put their hands on the objects made for the activity (plush pig and chicken, and plastic cells) so that each student can assemble their own virus. Rarely, a student has managed to assemble the same monitor virus. Thus, the monitors asked the students about the different types of flu viruses, about how a flu vaccine is made, informing in avian flu and swine flu the viruses recombined in another way, and also the difference between flu and cold.

\subsection{Sexually transmitted diseases}

This activity was carried out in environment 03 and stations 05 (dressing room) and 06 (interaction with the activity) and showed the students the prevention of STDs. The first station of this activity that the student has contact with is the 
dressing room. In this station there are materials in sequence: party props (ties, glasses, and scarves), gloves for personal protection, fluorescent paint. The monitor warned that putting on gloves or not was an option, and that after putting on gloves, students could paint themselves with fluorescent paint. After that, the students entered the tent (station 06) and participated in a controlled party with music and lighting for 5 minutes. As students had the option of using the glove or not. Those who didn't use it had their hands painted with fluorescent paint and were able to see later by ultraviolet light. All this practice makes it possible to introduce the subject of condom use for STDs in a way that causes minimal embarrassment and discomfort at the same time as there is an important visual stimulus. An objective way to reach an age group close to an active sex life, but shy to ask and get better information on the subject.

\section{Results}

The entire process was monitored by undergraduate and graduate students, who were also the actors in the explanatory videos. The interaction was presented in 5 public schools, with intense collaboration of the student and faculty, with 1300 students and more than $70 \%$ of participation.

To assess the practical result after the exposure, a survey was carried out with two interviewers external to the project, interviewing people from the school two months after the exposure to assess the immediate impact of the intervention, the results of which can be seen in table 1 .

The interviewees were unanimous as to the importance of exposure to punctuality, communication to students, strategy for setting up the exhibition and its importance, and only the flow of students was criticized, being considered very fast by most schools, with no time for contemplative exposure.

Table 1 Assessment of the immediate impact of the intervention

\begin{tabular}{|l|c|}
\hline Question & \% maximum satisfaction \\
\hline Meeting deadlines and schedules & $100 \%$ \\
\hline Appearance and dynamics of the materials used & $100 \%$ \\
\hline Communication with students & $100 \%$ \\
\hline Strategy for used for the preparation of the exhibition & $100 \%$ \\
\hline Clarity with which the information was passed & $66 \%$ \\
\hline Answering queries & $66 \%$ \\
\hline Friendliness and efficiency & $66 \%$ \\
\hline Division of the exhibition by space & $66 \%$ \\
\hline Suitability of topics to students & $66 \%$ \\
\hline Complexity of topics for students & $66 \%$ \\
\hline Exposure time & $33 \%$ \\
\hline
\end{tabular}

All comments praised the initiative, especially the University-Secondary Public School interaction. Some problems were mentioned by the interviewees in order to improve the exhibition, in particular, the size of the exhibition and the maximum number of participants, number and speed of carrying out the experiments; and difficulty of concentration and contention of students during the queue and waiting.

It was possible to evaluate some health parameters before the interaction, in a proactive population of students. This population consisted of students whose parents had authorized participation in a simultaneous scientific event. The questionnaire consisted of six multiple-choice questions, three questions to assess and prove the student/volunteer's vaccination status and three other questions about eating habits and laser therapy.

Regarding the vaccination status, 249 students answered the questionnaire, and only 205 students confirmed the vaccination with the MMR, by means of a copy of the national immunization card, and 12 students had failures in the scheme of any vaccine and 156 students were with the complete vaccination schedule. 
When the questionnaire on eating habits and restriction of contact with soil/sand was applied, we had 97 students who eat raw or undercooked meat and 144 do not eat raw or undercooked meat, 8 of which were vegetarians. Regarding soil restriction, 220 volunteers/children played in places such as sand ponds or fields, and 29 were restricted to contact with the soil.

\section{Discussion}

This interactive display of transmission of infectious agents progressed from direct contact, fomite transmission to interpersonal contact in a controlled party. The exhibition was interactive and brief, with the active participation of the students in the rehearsals and the revelation of outstanding events, such as interpersonal contamination at various levels of personal relationship with all the experiences worked during the exhibition, we managed to establish, in a friendly, integrated and progressive way, concepts hygiene and disease transmission mechanisms.

We show that events of this type, which raise awareness about the transmission and prevention of communicable diseases, including STD's, can be carried out interactively among students and without express mention of concepts derived from prejudice, allowing greater fixation and greater acceptance among students, parents and guardians.

Understanding the term "health education at school" is essential to contextualize and use the information presented in this article. School health education is an academic subject and is a critical component of a comprehensive education for children and youth.

Several of our findings during the exposure were consistent with previous research. For example, a previous study demonstrated that a layered approach to service delivery supports early identification of student needs and earlier service delivery [8].

Staff members and educators in this study also highlighted early identification and intervention as a benefit to an interprofessional approach to service delivery at school tiers. Also consistent with previous research we found that educators valued services that were (1) consistent, responsive, and timely; (2) it met the students' functional needs and impacted the entire class; and (3) were significantly incorporated into the classroom and into the lives of students [9, 10].

During the exhibition, we found that parents valued the services of interaction between university and school, where health professionals brought new content with new approaches, facilitating student learning.

Health education is comprehensive in nature and covers a variety of topics, including but not limited to the priority risk behaviors for adolescents identified by the CDC [11]. While health education must be comprehensive in nature, it also requires a focus on functional information (core knowledge) that is accurate, reliable, and reliable so that students can assess risks, clarify attitudes and beliefs, correct misperceptions about social norms, identify ways to avoid risky situations, examine internal and external influences, make relevant decisions and build personal and social competence, as demonstrated in our experiments.

Nobiling and Lyde suggested that health educators have "a responsibility to teach students functional knowledge that facilitates skill development, thus promoting healthy behavior change". Information in health education should be narrow in focus, functional and included for the purposes of skill development and behavior maintenance or behavior change [12].

An additional fundamental premise of this article is that health education alone is not sufficient to address and improve students overall health and well-being. In relation to the socioecological model, health education is focused on the individual and interpersonal levels of the model [13].

While interventions at these levels can be effective, interventions that include the broader community context, including institutional/organizational, community/neighborhood, and public policy levels, are even more effective [14]. Addressing population health through school health education requires a coordinated effort at all levels; of an effective health education curriculum and instruction through public policies that support and elevate the health education profession $[15,16]$.

The outcome of our exhibition was the construction of a script for the construction of videos and experiences, aiming to transfer to the school itself both in the construction of the videos to support the teacher's authority on the subject and the experiences in a didactic way, with the involvement of students. Interaction in an exhibition creates a more lasting 
type of memory and should be tried in the formation of hygiene concepts, in an age group where the correct formation of hygiene precepts is essential for full independence for safety.

\section{Conclusion}

Although the discussion and introduction to health in the school environment is positioned to play a role in the delivery of knowledge on individual and collective health, a significant and sustainable impact would best be achieved through a constant incentive base for the introduction of individual and collective health. If school health education is to assert its position as an integral participant in preparing children for a healthier life, school health education needs to carry out a collective, meaningful and sustainable research agenda that includes curriculum, instruction, professional preparation, and all school initiatives for implementation.

\section{Compliance with ethical standards}

\section{Acknowledgments}

This study was only possible to the financial support of the Rectory of Culture and Extension of the University of Sao Paulo. We are grateful for the operational support of the São Paulo State Department of Education, which allowed the study to be carried out in schools.

\section{Disclosure of conflict of interest}

The authors declare that there are no conflicts of interest in the preparation of this manuscript.

\section{Statement of informed consent}

This document is a clinical research protocol that will be conducted in compliance with all stipulations of this protocol, current national regulations, and the guidelines established by the Document of the Americas and the ICH Good Clinical Practice Guide.

\section{References}

[1] Brazil. Ministry of Health. Health Surveillance Secretariat. Health Care Secretariat. National Health Promotion Policy. 3rd ed. Brasília: Ministry of Health. 2010.

[2] Paim JS, Almeida Filho N. Collective health: a "new public health" or a field open to new paradigms? Rev Saude Publica. 1998; 32(4): 299-316.

[3] WHO. Ottawa charter for health promotion: An International Conference on. Health Promotion, the move towards a new public health. Ontario: Health and Welfare Canada; 1986. Geneva: World Health Organization. 1986.

[4] Minayo MCS, Gomes R. Ciência, Saúde Coletiva in the national and international context of scientific dissemination. Cienc Saude Colet. 2015; 20(7): 2013-22.

[5] Ceccim RB, Feuerwerker LCM. The quadrilateral of training for the health area: teaching, management, care and social control. Physis: Rev Saude Colet. 2004; 14(1): 41-65.

[6] Rumor PCF, Berns I, Heideman ITSB, Mattos LHL, Wosny AM. Health promotion in family health educational practices. Cogitare Sick. 2010; 15(4): 674-80.

[7] Association for Supervision and Curriculum Development (ASCD). Centers for Disease Control and Prevention (CDC). (2014). Whole school, whole child, and whole community: A collaborative approach to learning and health.

[8] Missiuna CA, Pollock NA, Levac DE, Campbell WN, Whalen SDS, Bennett SM, Russell DJ. Partnering for change: An innovative school-based occupational therapy service delivery model for children with developmental coordination disorder. Canadian Journal of Occupational Therapy. 2012; 79: 41-50.

[9] Pfeiffer DK, Pavelko SL, Hahs-Vaughn DL, Dudding CC. A national survey of speech-language pathologists' engagement in interprofessional collaborative practice in schools: Identifying predic- tive factors and barriers to implementation. Language, Speech, and Hearing Services in Schools. 2019; 50: 639-655. 
[10] Pollock N, Dix L, Sahagian-Whalen S, Campbell WN, Missiuna CA. Supporting occupational therapists implementing a capacity-building model in schools. Canadian Journal of Occupational Therapy. 2017; 84(4-5): $242-252$.

[11] Centers for Disease Control and Prevention (CDC). School connectedness. 2016.

[12] Nobiling BD, Lyde AR. From the school health education study to the National Health Education Standards: Concepts endure. Journal of School Health. 2015; 85(5): 309-317.

[13] McLeroy KR, Bibeau D, Steckler A, Glanz K. An ecological perspective on health promotion programs. Health Education Quarterly. 1988; 15: 351-377.

[14] Bassett-Gunter R, Yessis J, Manske S, Gleddie D. Healthy school communities in Canada. Health Education Journal. 2016; 75(2): 235-248.

[15] Cottrell R, Girvan J, McKenzie J, Seabert D. Principles and foundations of health promotion and educa- tion (6th ed.). Boston, MA: Pearson. 2015.

[16] Cottrell R, Girvan J, Seabert D, Spear C, McKenzie J. Principles and foundations of health promotion and education (7th ed.). New York, NY: Pearson. 2018. 